\title{
Randomised controlled trial of plasma protein fraction versus dopamine in hypotensive very low birthweight infants
}

\author{
A B Gill, A $M$ Weindling
}

\begin{abstract}
Around $20 \%$ of very low birthweight infants admitted to a neonatal intensive care unit become hypotensive within 24 hours of their admission. Standard treatment is either expansion of the circulating volume by the infusion of plasma protein fraction or by using dopamine to improve cardiac function. The purpose of this study was to investigate by a randomised controlled trial which was the most appropriate treatment.
\end{abstract}

Thirty nine infants were randomised to receive either plasma protein fraction or dopamine as first line treatment if they became hypotensive within 24 hours of admission to the neonatal intensive care unit. Seventeen of $19(89 \%)$ infants responded to dopamine, whereas only $9 / 20$ $(45 \%)$ responded to plasma protein fraction. The median dose of dopamine needed to increase the blood pressure to at least the 10 th centile was $7 \cdot 5 \mu \mathrm{g} / \mathrm{kg} / \mathrm{min}$ and was infused for a median duration of 18 hours.

These observations suggest that dopamine should be used earlier in the treatment of these infants than has previously been recommended.

(Arch Dis Child 1993; 69: 284-287)

Hypotension is one of the most common cardiovascular problems encountered in the early management of very low birthweight (VLBW) infants, affecting approximately $20 \%$ admitted to our unit in the first 24 hours after birth. A working party of the British Association of Perinatal Medicine and Royal College of Physicians stressed the importance of this problem, and defined hypotension as a mean systemic blood pressure less than an infant's gestational age in completed weeks. ${ }^{1}$ It recommended that, in the face of hypovolaemia, infants should be treated by volume expansion and that dopamine should be reserved for those infants who did not respond to infusions of plasma protein fraction. It further recommended that the dose of dopamine should begin at $10 \mu \mathrm{g} / \mathrm{kg} / \mathrm{min}$, but pointed out that there have been no formal clinical trials on which to base these recommendations.

The implication of these recommendations was that the two major causes of hypotension were hypovolaemia or myocardial dysfunction, or both, probably as a result of perinatal hypoxia and ischaemia. The case for hypovolaemia as the major aetiological factor specifically in hypotensive preterm infants is unproved $^{2}$ but there is evidence to suggest that myocardial dysfunction plays an important part in infants who become hypotensive in the first 24 hours after birth. ${ }^{3}$

In a pilot study we found that infusions of plasma protein fraction as a first line treatment for hypotension were ineffective in $50 \%$ of infants. These infants responded to inotropic drugs, but there was often a delay of two to three hours before their blood pressure recovered. This led to the suggestion that the earlier use of an inotropic drug might be more effective than plasma protein fraction in restoring the systemic blood pressure to normal in the first 24 hours after birth. To test this hypothesis we carried out a randomised controlled trial comparing infusions of plasma protein fraction with dopamine as a first line treatment for hypotension after infants had been admitted to the neonatal unit, and after appropriate measures to stabilise them had been carried out on the delivery suite. To our knowledge no previous studies in the VLBW infant have used dopamine before plasma protein fraction specifically for the treatment of hypotension.

\section{Patients and methods \\ PATIENTS}

Infants weighing less than $1501 \mathrm{~g}$ at birth and less than 24 hours old who had an indwelling arterial line for the measurement of systemic blood pressure were eligible for the study. If, in the view of the attending doctor, infants were felt to be clinically shocked before the insertion of the arterial line, then $20 \mathrm{ml} / \mathrm{kg}$ of plasma protein fraction was given via a peripheral line (resuscitation plasma protein fraction).

Infants who developed hypotension were enrolled into the study. As in the three years before this study, hypotension was taken as a mean blood pressure less than the 10th centile (as defined by Watkins et $a l^{4}$ ) for birth weight and postnatal age for at least 10 minutes, provided the infants were not receiving treatment likely to cause hypotension. Randomisation was by a random number generator and in blocks of 10 using sealed envelopes. Infants were allocated to one of two treatments.

In group 1 infants, plasma protein fraction containing $4.5 \%$ albumin was given over 30 minutes at a dose of $20 \mathrm{ml} / \mathrm{kg}$, allowing 30 minutes for a response. This treatment was repeated if the infant's blood pressure did not 
Table 1 Demographic and clinical data at the time of trial entry. Results expressed as median (range)

\begin{tabular}{|c|c|c|}
\hline & $\begin{array}{l}\text { Plasma protein fraction group } \\
\text { (group } 1 ; n=20 \text { ) }\end{array}$ & $\begin{array}{l}\text { Dopamine group } \\
\text { (group } 2 ; n=19)\end{array}$ \\
\hline \multicolumn{3}{|l|}{ Demographic } \\
\hline Birth weight & $867(604-1452)$ & $887(599-1420)$ \\
\hline Gestation (weeks) & $26 \cdot 5(24-20)$ & $27(23-31)$ \\
\hline Birthweight ratio* & $0.98(0.64-1 \cdot 3)$ & $0.99(0.66-1.45)$ \\
\hline \multicolumn{3}{|l|}{ Antenatal } \\
\hline $\mathrm{PIH}(\mathrm{No}) \dagger$ & 4 & 5 \\
\hline \multicolumn{3}{|l|}{ Trial } \\
\hline Time entered after birth (hours) & $8(2-16)$ & $8(3-15)$ \\
\hline \multicolumn{3}{|l|}{ No needing resuscitation } \\
\hline plasma protein fraction & 9 & 10 \\
\hline Mean systemic blood pressure $(\mathrm{mm} \mathrm{Hg})$ & $25(20-29)$ & $23(19-27)$ \\
\hline \multicolumn{3}{|l|}{ Ventilation } \\
\hline $\mathrm{FIO}_{2}(\%)$ & $70(30-100)$ & $60(25-100)$ \\
\hline $\mathrm{PIP}\left(\mathrm{cm} / \mathrm{H}_{2} \mathrm{O}\right)$ & $20(17-32)$ & $22(17-34)$ \\
\hline Rate $(/ \mathrm{min})$ & $60(30-80)$ & $60(30-75)$ \\
\hline $\mathrm{pH}$ & $7 \cdot 38(7 \cdot 21-7 \cdot 44)$ & $7 \cdot 36(7 \cdot 20-7 \cdot 44)$ \\
\hline a-A ratio & $0.11(0.04-0.32)$ & $0 \cdot 16(0 \cdot 06-0 \cdot 36)$ \\
\hline Haemoglobin $(g / l)$ & $149(93-177)$ & $145(55-185)$ \\
\hline
\end{tabular}

Statistical analysis using Mann-Whitney U test and $\chi^{2}$ (with Yates's correction). There was no significant difference ( $5 \%$ level) between the groups in any of the parameters.

*Birthweight ratio calculated as each individual patient's birth weight divided by the median for their gestational age.

$+\mathrm{PIH}=$ infants born to mothers with pregnancy induced hypertension and who were receiving

†PIH = infants born to mothers
treatment for hypertension.

treatment for hypertension.

$\mathrm{pH}=$ arterial pH; a-A ratio=arterial/alveolar oxygen ratio (a marker of the severity of hyaline membrane disease ${ }^{26}$ ).

Table 2 Morbidity and mortality by group. Results expressed as medians or actual numbers (\%)

\begin{tabular}{lcc}
\hline & $\begin{array}{c}\text { Plasma protein fraction group } \\
\text { (group 1; } n=20)\end{array}$ & $\begin{array}{c}\text { Dopamine group } \\
\text { (group 2; } n=19)\end{array}$ \\
\hline PVH $^{\star}$ & & \\
Grade 1 (No (\%)) & $3(15)$ & $8(42 \%)$ \\
Grade 2 (No (\%)) & $11(55)$ & $7(37 \%)$ \\
Grade 3 (No (\%)) & $6(30)$ & $4(21 \%)$ \\
Duration of PPV (days) $t$ & 10 & 12 \\
Chronic lung disease (No (\%)) & $9(55)$ & $12(58)$ \\
Retinopathy of prematurity (No (\%)) & $7(65)$ & $8(67)$ \\
Deaths & $5(25)$ & $3(16)$ \\
\hline
\end{tabular}

Statistical analysis using Mann-Whitney $U$ test and $\chi^{2}$ analysis with Yates's correction. There was no significant difference ( $5 \%$ level) between the groups.

*Periventricular haemorrhage graded according to Cooke's classification. ${ }^{5}$

$+\mathrm{PPV}=$ positive pressure ventilation

rise above the 10 th centile. If after two hours their blood pressure had still not reached the 10 th centile, then infants were treated with dopamine as outlined in the following.

In group 2 infants, dopamine was started at a rate of $5 \mu \mathrm{g} / \mathrm{kg} / \mathrm{min}$. This rate was increased in steps of $2 \cdot 5 \mu \mathrm{g} / \mathrm{kg} / \mathrm{min}$ every 30 minutes to a maximum of $10 \mu \mathrm{g} / \mathrm{kg} / \mathrm{min}$ until the blood pressure reached the 10 th centile. If this level was not reached after two hours, the infant was given plasma protein fraction as outlined for infants in group 1.

Infusions were given through either the unbilical arterial line or a peripheral venous line. Infants who did not respond to either treatment were then treated at the discretion of the attending doctor.

The outcome of the study was defined by whether or not the first line treatment was successful in restoring the mean blood pressure to at least the 10 th centile within two hours of entry into the study.

Antenatal and postnatal data were collected on all infants. The diagnosis of periventricular haemorrhage was made using transcranial ultrasound performed at least three times in the first week after birth. The degree of periventricular haemorrhage was graded according to the classification of Cooke $^{5}$ : grade 1 , subependymal haemorrhage; grade 2 , intraventricular haemorrhage with or without ventricular dilatation; and grade 3, intraventricular haemorrhage with parenchymal extension. Chronic lung disease was defined as oxygen dependency at 28 days with characteristic changes on a chest radiograph, after ventilation for hyaline membrane disease (classification of Northway et $a l^{6}$ ).

Retinopathy of prematurity was diagnosed by a consultant ophthalmologist between 32 and 34 weeks postconceptional age.

\section{SAMPLE SIZE}

To improve our first line success rate by $40 \%$ we estimated we would need 20 patients in each group for the study to have $80 \%$ power with a significance level of $5 \%$.

\section{STATISTICAL ANALYSIS}

Statistical comparison was using the MannWhitney $U$ test and $\chi^{2}$ analysis with Yates's correction. Statistical significance was taken at the $5 \%$ level.

The study was approved by the Liverpool district paediatric ethics committee. The question of formal parental consent was considered carefully by the committee and they did not insist on signed consent being obtained. Parents were, however, informed about the nature of the study.

\section{Results}

Thirty nine VLBW infants developed hypotension in the first 24 hours after birth. Twenty infants received plasma protein fraction and 19 received dopamine as first line treatment. Table 1 shows the de1:ographic antenatal and clinical data at entry to the trial. There was no statistically significant difference between the two groups in any of the parameters studied. Nine of $20(45 \%)$ infants in the plasma protein fraction group and $10 / 19(53 \%)$ infants in the dopamine group received resuscitation plasma protein fraction before the insertion of the arterial line $\left(\chi^{2}=0.45 ; p=0.52\right)$.

Seventeen of 19 (89\%) infants responded to dopamine whereas only $9 / 20$ (45\%) responded to plasma protein fraction $\left(\chi^{2}=6 \cdot 8^{\circ}, p=0.009\right)$. In infants who received dopamine (30/39), as either a first treatment or after plasma protein fraction, the median dose of dopamine required was $7.5 \mu \mathrm{g} / \mathrm{kg} / \mathrm{min}$ and this was infused for a median duration of 18 hours (interquartile range 8-28 hours). The response to first line treatment was not influenced by treatment of the mother for hypertension or the use of resuscitation plasma protein fraction.

Four of $39(10 \%)$ infants did not respond to either treatment, three in the plasma protein fraction group and one in the dopamine group. Of these, one of the infants in the plasma protein fraction group and the infant in the dopamine group responded to the addition of dobutamine. The remaining two infants in the plasma protein fraction group did not respond to any additional treatment and died within 24 hours of entry. 
Table 2 shows the long term morbidity and mortality in the two groups. There was no significant difference in the severity of periventricular haemorrhage or the number of infants who died in each group. In those who survived, the duration of positive pressure ventilation and the percentage developing chronic lung disease and retinopathy of prematurity were similar in the two groups. The proportions are based on the number of infants in whom it was possible to make the diagnosis of chronic lung disease and retinopathy of prematurity.

\section{Discussion}

Survival of VLBW infants has improved in recent years, particularly in those with a birth weight less than $1000 \mathrm{~g}^{7}{ }^{7}$ The use of positive pressure ventilation and more recently the common use of antenatal steroids and intratracheal surfactants have undoubtedly contributed to this, but the incidence of periventricular haemorrhage remains unchanged. ${ }^{8-10}$ Postnatal care has been focused on maintaining physiological indices, such as blood pressure, within a normal range. ${ }^{11}$ Many studies have found that hypotension is associated with periventricular haemorrhage. ${ }^{4}{ }^{12-16}$ In two studies specifically examining its role, Watkins et $\mathrm{al}^{4}$ and Miall-Allen et $a l^{15}$ showed that infants who had periods of hypotension for more than one hour appeared more likely to develop periventricular haemorrhage than normotensive control infants. Bada et al found that the hypotensive episodes appeared to precede the development of periventricular haemorrhage. ${ }^{16}$ Direct causation has not been proved, however.

The treatment of hypotension usually includes waiting for a lack of response to plasma protein fraction before prescribing dopamine. The use of this strategy implies that hypovolaemia is considered to be a more important factor than myocardial dysfunction. Although preterm infants with hyaline membrane disease have been shown to be relatively hypovolaemic compared with those without hyaline membrane disease, ${ }^{17-19}$ the case for hypovolaemia as the major aetiological factor in hypotension has not been proved. In fact, Barr et al, in a study using radiolabelled albumin, showed that hypotensive infants had similar circulating plasma and blood volumes to normotensive control infants. ${ }^{2}$ They did not show a significant improvement in the blood pressure after an infusion of plasma protein fraction despite an increase in circulating blood volume. Using two dimensional and Doppler echocardiography, we have shown that cardiac dysfunction is present in nearly $50 \%$ of VLBW infants before they become hypotensive. ${ }^{3}$

It seems likely that in the first 24 hours after birth the aetiology of hypotension will not always be solely due to either hypovolaemia or myocardial dysfunction, but rather a combination of the two. Intrapartum asphyxia leading to fetal myocardial dysfunction could potentially cause pooling of blood in the placenta and this might result in additional hypovolaemia. Similarly, antepartum haemorrhage, if severe, may not only cause hypovolaemia but is likely to lead to myocardial ischaemia. Treatment of one and not the other is unlikely to increase the infant's blood pressure. Most neonatologists, however, use volume expansion first before giving inotropic drugs. Unfortunately, with present monitoring on most neonatal units it is not possible to determine if infants are purely hypovolaemic, have myocardial dysfunction, or a combination of the two, as the symptoms and signs are similar. Our study showed that dopamine was more effective than plasma protein fraction in raising the blood pressure of VLBW infants who became hypotensive during the first 24 hours after their admission to the neonatal intensive care unit. This does not imply that myocardial dysfunction is the sole cause, but suggests that waiting for a lack of response to plasma protein fraction before using dopamine is inappropriate.

Approximately $50 \%$ of all VLBW infants (normotensive and hypotensive) admitted to our neonatal intensive care unit will receive resuscitation plasma protein fraction for the treatment of poor perfusion or metabolic acidosis, or both, before their blood pressure is measured, but only $10 \%$ of these will become hypotensive and require treatment. The use of resuscitation plasma protein fraction may mean that hypovolaemia was treated in a significant proportion of infants before the blood pressure was measured. This suggests that those infants who subsequently develop hypotension are likely to have myocardial dysfunction or more severe hypovolaemia, or both. The fact that similar numbers of infants in the two groups received 20 $\mathrm{ml} / \mathrm{kg}$ of resuscitation plasma protein fraction before an invasive measure of blood pressure was available, and that there was no relation with subsequent response to treatment strengthens the argument for the early use of dopamine.

In our study $23 / 30(77 \%)$ infants who received dopamine, either as first line treatment or after plasma protein fraction, responded at a dose of $7.5 \mu \mathrm{g} / \mathrm{kg} / \mathrm{min}$ or less. Four of $39(10 \%)$ infants did not respond to either treatment, two dying within 24 hours of entry, and the other two infants responding to the addition of dobutamine. Dopamine has been extensively used in preterm and term infants and appears to have dose dependent actions. ${ }^{20-23}$ There is debate as to whether the dose response is reduced in VLBW infants due to possible receptor immaturity, ${ }^{24}$ thereby requiring higher doses to effect the same response. It appears to act either directly or indirectly on the sympathetic nerve receptors throughout the body, most notably in the heart and kidney. Padbury et al studied dopamine pharmacokinetics in preterm and term infants at doses up to $8 \mu \mathrm{g} / \mathrm{kg} / \mathrm{min} .{ }^{2325}$ They found that dopamine appeared to have a positive inotropic effect at a lower dose than its chronotropic effect. The infants in our study were significantly smaller than those of 
Padbury et al, but the response by most of the infants to a dose of dopamine of either 5 or 7.5 $\mu \mathrm{g} / \mathrm{kg} / \mathrm{min}$ suggests adequate receptor maturity and questions the need for doses greater than $10 \mu \mathrm{g} / \mathrm{kg} / \mathrm{min}$.

The early use of dopamine did not affect the number of infants developing grade 3 periventricular haemorrhage. As local and systemic factors have been implicated in its aetiology, it was unlikely that a single therapeutic manoeuvre would reduce its incidence. It may be that research needs to focus more on tissue function and the blood pressure needed by an individual subject to optimise it before being able to decide whether a low blood pressure warrants therapeutic intervention. Until proved otherwise, however, it remains the view of most neonatologists that hypotension should be treated. The results of this study suggest that dopamine should be considered at the outset for the treatment of hypotension in VLBW infants.

1 Joint Working Party of the British Association of Perinatal Medicine and Research Unit of the Royal College of Physicians. Development of audit measures and guidelines for good practice in the management of neonatal respiratory distress syndrome. Arch Dis Child 1992; 67: piratory

2 Barr PA, Bailey PE, Summers J, Cassady G. Relation between arterial blood pressure and blood volume and between arterial blood pressure and blood volume and effect of infused alb

3 Gill AB, Weindling AM. Cardiac function in the shocked very low birthweight infant. Arch Dis Child 1993; 68: $17-21$.

4 Watkins AMC, West CR, Cooke RWI. Blood pressure and cerebral haemorrhage and ischaemia in very low birthweight infants. Early Hum Dev 1989; 19: 103-10.

5 Cooke RWI. Early and late cranial ultrasonographic appearances and outcome in very low birthweight infants. Arch Dis Child 1987; 62: 931-7.

6 Northway WH, Rosan RC, Porter DY. Pulmonary disease respirator therapy of hyaline membrane disease; respirator therapy of hyaline membrane disease; bronchop $357-8$.

7 Cooke RWI. Annual audit of neonatal morbidity in preterm infants. Arch Dis Child 1992; 67: 1174-6.
8 McCord FB, Curstedt T, Halliday HL. Surfactant treatment and the incidence of intraventricular haemorthage in ment and the incidence of intraventricular haemorrhage in 63: $10-6$.

9 Morley CJ. Surfactant therapy for premature babies. A review of clinical trials. Arch Dis Child 1991; 66: 445-50

0 The OSIRIS Collaborative Group. Early versus late delayed neonatal administration of synthetic surfactant. The judgement of OSIRIS. Lancet 1992; 340: 1363-9.

11 Miall-Allen VM, Whitelaw AGL. Response to dopamine and dobutamine in the preterm infant less than 30 weeks gestation. Crit Care Med 1989; 17: 1166-9.

12 Cooke RWI. Factors associated with periventricular haemorrhage in very low birthweight infants. Arch Dis Child 1981; 56: 425-31.

13 Levene MI, Fawer CL, Lamont RF. Risk factors in the development of intraventricular haemorrhage in the

14 Szymonowicz W, Yu VYH, Wilson FE. Antecedents of periventricular haemorrhage in infants weighing $1250 \mathrm{~g}$ or less at birth. Arch Dis Child 1984; 59: 13-7.

15 Miall-Allen VM, De Vries LS, Whitelaw AGL. Mean arterial blood pressure and neonatal cerebral lesions. Arch Dis Child 1987; 62: 1068-9.

16 Bada HS, Korones SB, Perry EH, et al. Mean arterial blood pressure changes in premature infants and those at risk for intraventricular haemorrhage. $f$ Pediatr 1990; 117: 607-14.

17 Brown EG, Krouskop RW, McDonnell FE, Sweet AY. Blood volume and blood pressure in infants with respiratory distress. 7 Pediatr $1975 ; 87: 1133-8$

18 Faxelius G, Raye J, Gutberlet $R$, et al. Red cell volume measurements and acute blood loss in high risk newborn infants. F Pediatr 1977; 90: 273-8

19 Linderkamp G, Versmold HT, Fendel H, Riegel KP, Berke $\mathrm{K}$. Association of neonatal respiratory distress with birth asphyxia and deficiency of red cell mass in premature infants. Eur $\mathcal{F}$ Pediatr 1978; 129: 167-73.

20 Disessa TG, Leitner M, Ti CC. Cardiovascular effects of dopamine in the severely asphyxiated neonate. $f$ Pediatr 1981; 99: 772-6.

21 Seri I, Tulassey T, Kiszel J, Machay T, Csomor S. Cardiovascular response to dopamine in hypotensive preterm neonates with severe hyaline membrane disease. Eur 7 Pediatr 1984; 142: 3-9.

22 Walther FJ, Bijan Siassi PD, Ramadan NA, Wu PYK. Cardiac output in newborn infants with transient myocardial dysfunction. $\mathcal{F}$ Pediatr 1985; 107: 781-5

23 Padbury JF, Agata Y, Baylen BG, et al. Dopamine pharmacokinetics in critically ill newborn infants. $\mathcal{F}$ Pediatr 1986; 110: 293-8.

24 Zaritskey A, Chernow B. Use of catecholamines in paediatrics. $\mathcal{f}$ Pediatr 1984; 105: 341-55.

25 Padbury JF, Agata Y, Baylen BG, et al. The pharmacokinetics of dopamine in critically ill newborn infants. f Pediatr 1990; 117: 472-6.

26 Gilbert R, Keighley GF. The arterial/alveolar oxygen tension ratio: an index of gas exchange applicable to varying oxygen concentrations. Am Rev Respir Dis 1974; 109: $142-5$. 